\title{
Suppression of circulating AP001429.1 long non-coding RNA in obese patients with breast cancer
}

\author{
HANI CHOUDHRY ${ }^{1,2^{*}}$, MOHAMMED A. HASSAN $^{1,3 *}$, \\ ABDULRAHMAN L. AL-MALKI ${ }^{1}$ and KALTOOM A. AL-SAKKAF ${ }^{4,5}$ \\ ${ }^{1}$ Department of Biochemistry, Faculty of Science, ${ }^{2}$ Cancer and Mutagenesis Unit, King Fahd Medical Research Center, \\ King Abdulaziz University, Jeddah 21589, Kingdom of Saudi Arabia; ${ }^{3}$ Department of Basic Medical Sciences, \\ College of Medicine and Health Sciences, Hadhramout University, Mukalla, Republic of Yemen; \\ ${ }^{4}$ Department of Medical Laboratory Technology, Faculty of Applied Medical Sciences; ${ }^{5}$ Immunology Unit, \\ King Fahd Research Medical Centre, King Abdulaziz University, Jeddah 21589, Kingdom of Saudi Arabia
}

Received December 20, 2020; Accepted March 31, 2021

DOI: 10.3892/ol.2021.12769

\begin{abstract}
Long non-coding RNAs (lncRNAs), a type of cellular RNA, play a critical regulatory role in several physiological developments and pathological processes, such as tumorigenesis and tumor progression. Obesity is a risk factor for a number of serious health conditions, including breast cancer (BC). However, the underlying mechanisms behind the association between obesity and increased $\mathrm{BC}$ incidence and mortality remain unclear. Several studies have reported changes in lncRNA expression due to obesity and BC, independently encouraging further investigation of the relationship between the two in connection with lncRNAs. The present study was designed to first screen for the expression of 29 selected lncRNAs that showed a link to cancer or obesity in the blood of a selected cohort of 6 obese and 6 non-obese patients with BC. The expression levels of significantly expressed lncRNAs, AP001429.1, PCAT6, P5549, P19461 and $P 3134$, were further investigated in a larger cohort of 69 patients with BC (36 obese and 33 non-obese), using reverse transcription-quantitative polymerase chain reaction. Results showed not only that AP001429.1 remained significantly downregulated in the larger cohort $(\mathrm{P}=0.002)$, but also that it was associated with several clinicopathological characteristics, such as negative HER2 status, negative E-cadherin expression, negative vascular invasion, negative margin invasion and LCIS. These findings suggest that obesity may have a role in
\end{abstract}

Correspondence to: Dr Mohammed A. Hassan, Department of Biochemistry, Faculty of Science, King Abdulaziz University, Building A-90, Al-Oloum Street, Jeddah 21589, Kingdom of Saudi Arabia

E-mail:maah3512@gmail.com

${ }^{*}$ Contributed equally

Key words: breast cancer, obesity, long non-coding RNA, AP001429.1, molecular biomarker, therapeutic target inhibiting AP001429.1 expression, which may serve as a novel potential biomarker and therapeutic target for BC.

\section{Introduction}

Breast cancer (BC) is the most common type of cancer, having the highest incidence and being the leading cause of death from cancer in women worldwide. Globally, in 2018, more than 2 million cases of BC were newly diagnosed in women, with $>625,000$ deaths due to this disease. It was also reported that, in 2018, BC accounted for $31.6 \%$ of all newly diagnosed cancer cases in women in Saudi Arabia (1). Obesity poses a serious growing public health problem worldwide (2). According to estimates by the World Health Organization (WHO), in 2016, there were $\sim 2$ billion overweight adults, of whom $>650$ million were considered obese (3). In Saudi Arabia, the prevalence of obesity is higher among women than men (4).

Obesity is one of the risk factors of cancer and may be involved with $20 \%$ of several types of cancer, including colorectal, postmenopausal breast, endometrial, renal and prostate cancers (5). Obesity has been reported to be a risk factor in BC, especially in postmenopausal women, and may associate with an increased incidence, a poor prognosis and decreased survival rate (6-8). Focusing on the molecular connection between BC and obesity could provide an important tool for researchers to clarify the underlying mechanisms, which may help identify novel prognostic biomarkers and therapeutic targets for BC.

Long non-coding RNAs (lncRNAs) are a class of untranslated regulatory RNA consisting of $>200$ nucleotides, which are considered important cellular RNA types that play critical regulatory roles in numerous biological processes, including genomic imprinting, chromatin modeling and post-transcriptional regulation (9); they have also been associated with various human diseases, including a variety of cancer types, such as breast, gastric and colorectal cancers $(10,11)$. Although numerous lncRNAs have differential expression levels that may act as oncogenes or tumor suppressors (12), their biological functions and molecular mechanisms remain largely unknown (13). 
Obesity involves profound epigenetic changes and affects the expression level of obesity-associated lncRNAs, which may be involved in cancer initiation and/or progression and affect the outcome of cancer therapy (14). Moreover, the expression levels of several lncRNAs, such as lncRNA P5549 (P5549), lncRNA P19461 (P19461) and lncRNA P3134 (P3134), are differentially expressed in obesity (15). However, the contribution of these IncRNAs to obesity in relation to $\mathrm{BC}$ is still unclear. Although several mechanisms have been proposed (16), the molecular association between obesity and BC is still not well understood and remains under investigation (17). Moreover, the role of lncRNAs in obesity-related cancer also remains unclear (16). Therefore, the present study was designed to evaluate the expression level of 29 selected IncRNAs that have previously been linked to cancer or obesity (Table I) $(15,16,18-52)$ in the whole blood of obese patients with $\mathrm{BC}$ compared with that in non-obese patients with $\mathrm{BC}$, using reverse transcription-quantitative polymerase chain reaction (RT-qPCR). Subsequently, the expression levels of significantly differentially expressed lncRNAs were assayed in a larger cohort and the associations with the baseline and clinicopathological characteristics of the patients were assessed.

This study could lead to a better understanding of the expression status of circulating lncRNAs and provide new insights into the IncRNAs involved in the interaction between obesity and $\mathrm{BC}$, which could serve as a potential biomarker in $\mathrm{BC}$ prognosis.

\section{Materials and methods}

Study subjects. The study included 69 BC female patients who attended between October 2016 and September 2017 the Unit of Mammography, Department of Radiography at King Abdulaziz University Hospital (KAUH; Jeddah, Saudi Arabia), where they were diagnosed with BC. No patient had yet undergone any treatment and patients with recurrent $\mathrm{BC}$ were also excluded. Depending on the body mass index (BMI) differentiation (53), the BC patients were categorized as non-obese, which included lean and overweight (BMI <30 kg/m²; n=33), and obese (BMI $\geq 30 \mathrm{~kg} / \mathrm{m}^{2} ; \mathrm{n}=36$ ). All patients provided written informed consent. The KAUH Unit of Biomedical Ethics Research Committee approved the study (approval number, HA-02-J-008). The patient information and sociodemographic characteristics were obtained through a standard questionnaire by interview. A standard well-established method was used to collect anthropometric data following WHO recommendations (53). The clinicopathological characteristics and clinical interpretation were provided by the consultants, radiologist and pathologist, as described previously $(54,55)$.

Blood sample collection and storage. According to the manufacturer's instruction, whole blood samples were collected in PAXgene ${ }^{\mathrm{TM}}$ blood RNA tubes (Qiagen, Inc.), and then stored at $-80^{\circ} \mathrm{C}$ until being used for RNA extraction.

RNA extraction. Total RNA was isolated from the whole blood of 69 patients with BC using the PAXgene blood RNA kit (Qiagen, Inc.). The quantity and quality of the extracted
RNA were verified by DeNovix DS-11 Spectrophotometer (DeNovix, Inc.). The RNA samples were also separated in $1.2 \%$ agarose gel electrophoresis to check the quality. The RNA samples were aliquoted and stored at $-80^{\circ} \mathrm{C}$ until being used for complementary DNA (cDNA) synthesis.

Complementary DNA (cDNA) synthesis. Total RNA (400 ng) from each BC sample was reverse transcribed to generate cDNA using a QuantiTect Reverse Transcription (RT) kit (Qiagen, Inc.) following the manufacturer's protocols. The cDNA was stored at $-20^{\circ} \mathrm{C}$ until required.

Quantitative polymerase chain reaction ( $q P C R$ ). The gene expression levels of 29 lncRNAs, selected according to a suggested role in cancer or obesity as reported by the literature, including by our previous study (43) (Table I), were evaluated in the blood of obese and non-obese patients with BC by qPCR. Each experiment was run in duplicate in 96-well plates using a Bio-Rad IQ SYBR Green mix and the CFX Connect ${ }^{\mathrm{TM}}$ Real-Time PCR Detection system (both Bio-Rad Laboratories, Inc.), according to the manufacturers' protocols and guidelines. The qPCR reactions were carried out as follows: Initial cycle for $30 \mathrm{sec}$ at $95^{\circ} \mathrm{C}$; followed by 40 cycles of $15 \mathrm{sec}$ at $98^{\circ} \mathrm{C}$, and $30 \mathrm{sec}$ at $60^{\circ} \mathrm{C}$. The amplification product was checked at the end of each cycle, and the purity of amplification products was checked by the analysis of melting curves. The lncRNA expression levels were normalized using the housekeeping gene glyceraldehyde 3-phosphate dehydrogenase $(G A P D H)$ as an internal control for relative expression quantification. The primer pairs of target lncRNAs and reference genes were designed over two different exons using the Primer3 web tool and assessed using the In-Silico PCR tool for human genome assembly GRCh38 (hg38), provided by the University of California, Santa Cruz Genome Browser (http://genome. ucsc.edu/index.html). The sequences of the primers are presented in Table II. The relative expression quantification was calculated using the relative expression software tool (REST 2009) version 2.0.13 (56) and the comparative Cq method $\left(2^{-\Delta \Delta \mathrm{Cq}}\right)(57)$.

Statistical analysis. GraphPad Prism version 8.0.1 (GraphPad Software) was used to evaluate the statistical analyses of the obtained data using an unpaired, two-tailed t-test to determine the significant differences in the gene expression between groups. Moreover, $\chi^{2}$ and Kruskal-Wallis tests (one-way ANOVA) with a two-tailed P-value were used to test the distribution of categorical baseline and clinicopathological characteristics between obese and non-obese patients with BC. $\mathrm{P} \leq 0.05$ was used to indicate a statistically significant difference. Bonferroni's correction was applied and the corrected P-value of $\leq 0.05$ used for multiple comparisons of AP001429.1 expression level and patient baseline and clinicopathological characterizations. The data are presented as the mean \pm standard error of the mean (SEM). Receiver operating characteristic (ROC) curves were generated to evaluate the sensitivity and specificity of $A P 001429.1$ as a potential biomarker, using its gene expression values $\left(2^{-\Delta \mathrm{Cq}}\right)$ of obese and non-obese patients with BC in the easyROC web-tool (ver.1.3.1; http://www. biosoft.hacettepe.edu.tr/easyROC/). 
Table I. Selected lncRNAs associated with different cancer types, BC or obesity.

\begin{tabular}{|c|c|c|c|c|c|}
\hline lncRNA & Full name & Expression status & Biological functions & Associated diseases & (Refs.) \\
\hline AC011891.5 & IncRNA AC011891.5 & Upregulated & $\begin{array}{l}\text { Positively correlated } \\
\text { with BMI }\end{array}$ & Obesity & (18) \\
\hline ANRIL & lncRNA ANRIL & Upregulated & Homeostatic regulator & Several cancer types & (16) \\
\hline B4GALT1-AS1 & lncRNA B4GALT1-AS1 & Upregulated & $\begin{array}{l}\text { Promotes cancer cell } \\
\text { stemness and migration }\end{array}$ & Colon cancer & (19) \\
\hline$B C A R 4$ & $\begin{array}{l}\text { BC anti-estrogen } \\
\text { resistance } 4\end{array}$ & Upregulated & $\begin{array}{l}\text { Induces cancer cell } \\
\text { proliferation and migration }\end{array}$ & $\mathrm{BC}$ & (20) \\
\hline Blnc1 & $\operatorname{lncRNA} B \operatorname{lnc} 1$ & Upregulated & $\begin{array}{l}\text { Controls adipocyte } \\
\text { differentiation }\end{array}$ & Energy homeostasis & $(21,22)$ \\
\hline CCAT1 & $\begin{array}{l}\text { Colon cancer-associated } \\
\text { transcript } 1\end{array}$ & Upregulated & $\begin{array}{l}\text { Promotes cancer cell } \\
\text { proliferation, migration } \\
\text { and invasion }\end{array}$ & Cancer cell & $(23-25)$ \\
\hline CCAT2 & $\begin{array}{l}\text { Colon cancer-associated } \\
\text { transcript } 2\end{array}$ & Upregulated & $\begin{array}{l}\text { Promotes cancer cell } \\
\text { proliferation, migration } \\
\text { and invasion }\end{array}$ & Several carcinomas & (26) \\
\hline$H-19$ & $\begin{array}{l}\text { H19, imprinted maternally } \\
\text { expressed transcript }\end{array}$ & Upregulated & $\begin{array}{l}\text { Inhibits adipocyte } \\
\text { differentiation and } \\
\text { improves insulin } \\
\text { sensitivity and } \\
\text { mitochondrial biogenesis }\end{array}$ & $\begin{array}{l}\text { Obesity and numerous } \\
\text { cancer types, including } \\
\text { BC }\end{array}$ & $(16,27)$ \\
\hline HOTAIR & $\begin{array}{l}\text { HOX transcript } \\
\text { antisense RNA }\end{array}$ & Upregulated & $\begin{array}{l}\text { Abdominal preadipocyte } \\
\text { differentiation }\end{array}$ & Several cancer types & (16) \\
\hline LINC00968 & $\begin{array}{l}\text { Long intergenic } \\
\text { non-protein coding } \\
\text { RNA } 968\end{array}$ & Upregulated & $\begin{array}{l}\text { Positively correlated } \\
\text { with BMI }\end{array}$ & Obesity & (18) \\
\hline LINCADL & $\begin{array}{l}\text { lincRNA } \\
\text { adipogenesis- and } \\
\text { lipogenesis-associated }\end{array}$ & Upregulated & $\begin{array}{l}\text { Regulates adipocyte } \\
\text { differentiation and fatty } \\
\text { acid synthesis }\end{array}$ & Obesity & (28) \\
\hline MALAT-1 & $\begin{array}{l}\text { Metastasis-associated } \\
\text { lung adenocarcinoma } \\
\text { transcript } 1\end{array}$ & Upregulated & $\begin{array}{l}\text { Promotes cancer cell } \\
\text { proliferation, migration } \\
\text { and invasion, and plays a } \\
\text { role in tumorigenesis } \\
\text { and/or metastasis }\end{array}$ & Various cancer types & $(29-31)$ \\
\hline NEAT1 & $\begin{array}{l}\text { Nuclear-enriched } \\
\text { abundant transcript } 1\end{array}$ & Upregulated & $\begin{array}{l}\text { Regulates adipogenic } \\
\text { differentiation }\end{array}$ & Obesity & $(32,33)$ \\
\hline PANDAR-1 & $\begin{array}{l}\text { Promoter of CDKN1A } \\
\text { antisense DNA damage- } \\
\text { activated RNA } 1\end{array}$ & Upregulated & $\begin{array}{l}\text { Induces cancer cell } \\
\text { proliferation, invasion } \\
\text { and activation of cell } \\
\text { epithelial-mesenchymal } \\
\text { transition pathway }\end{array}$ & Gastric cancer & $(34-36)$ \\
\hline PCAT6 & $\begin{array}{l}\text { Prostate cancer-associated } \\
\text { ncRNA transcript } 6\end{array}$ & Upregulated & $\begin{array}{l}\text { Promotes cancer cell } \\
\text { growth }\end{array}$ & Numerous cancer types & $(37-40)$ \\
\hline$R P 11-20 G 13.3$ & LincRNA RP11-20G13.3 & Upregulated & $\begin{array}{l}\text { Attenuates adipogenesis } \\
\text { of preadipocytes }\end{array}$ & Obesity & (18) \\
\hline ZFAS1 & Zinc finger antisense 1 & Upregulated & $\begin{array}{l}\text { Promotes cancer cell } \\
\text { proliferation and } \\
\text { metastasis }\end{array}$ & Various cancer types & $(41,42)$ \\
\hline AP001429.1 & LncRNA AP001429.1 & Upregulated & $\begin{array}{l}\text { Negatively correlated } \\
\text { with BMI }\end{array}$ & Obesity & (43) \\
\hline GAS5 & Growth arrest-specific 5 & Downregulated & $\begin{array}{l}\text { Inhibits cancer cell } \\
\text { proliferation and } \\
\text { promotes apoptosis }\end{array}$ & $\begin{array}{l}\text { Obesity and numerous } \\
\text { types of cancer }\end{array}$ & $(44-47)$ \\
\hline
\end{tabular}


Table I. Continued.

\begin{tabular}{|c|c|c|c|c|c|}
\hline lncRNA & Full name & Expression status & Biological functions & Associated diseases & (Refs.) \\
\hline$G Y G 2 P 1$ & $\begin{array}{l}\text { Glycogenin } 2 \\
\text { pseudogene } 1\end{array}$ & Downregulated & $\begin{array}{l}\text { Negatively associated with } \\
\text { BMI, fasting insulin and } \\
\text { triglycerides, and may } \\
\text { play a role in the } \\
\text { pathogenetic mechanism }\end{array}$ & Obesity & (18) \\
\hline MEG3 & $\begin{array}{l}\text { Maternally expressed } \\
\text { gene } 3\end{array}$ & Downregulated & Inhibits adipogenesis & Obesity & $(48)$ \\
\hline OLMALINC & $\begin{array}{l}\text { Oligodendrocyte } \\
\text { maturation-associated } \\
\text { lincRNA }\end{array}$ & Downregulated & $\begin{array}{l}\text { Increases expression of } \\
\text { lipid metabolism genes }\end{array}$ & Obesity & (18) \\
\hline P19461 & lncRNA P19461 & Downregulated & $\begin{array}{l}\text { Negatively correlated } \\
\text { with BMI }\end{array}$ & Obesity & $(15)$ \\
\hline$P 21015$ & lncRNA P21015 & Downregulated & $\begin{array}{l}\text { Negatively correlated } \\
\text { with BMI }\end{array}$ & Obesity & (15) \\
\hline P5549 & lncRNA P5549 & Downregulated & $\begin{array}{l}\text { Negatively correlated } \\
\text { with BMI }\end{array}$ & Obesity & $(15)$ \\
\hline$R P 11-529 H 2.1$ & lincRNA RP11-529H2.1 & Downregulated & $\begin{array}{l}\text { Negatively correlated } \\
\text { with BMI }\end{array}$ & Obesity & (18) \\
\hline$R P 11-559 N 14.5$ & lncRNA RP11-559N14.5 & Downregulated & $\begin{array}{l}\text { Involve in the AMPK } \\
\text { signaling pathway, } \\
\text { adipocytokine signaling } \\
\text { pathway and insulin } \\
\text { resistance }\end{array}$ & Obesity & $(18)$ \\
\hline SARl & $\begin{array}{l}\text { IncRNA steroid receptor } \\
\text { RNA activator } 1\end{array}$ & Downregulated & $\begin{array}{l}\text { Regulates adipogenesis } \\
\text { and insulin sensitivity }\end{array}$ & Obesity & $(49)$ \\
\hline$U C A 1$ & $\begin{array}{l}\text { Urothelial } \\
\text { carcinoma-associated } 1\end{array}$ & Downregulated & $\begin{array}{l}\text { Promotes cancer cell } \\
\text { migration and invasion }\end{array}$ & Multiple cancer types & $(50-52)$ \\
\hline
\end{tabular}

lncRNA, long non-coding RNAs; lincRNA, long intergenic ncRNA; BC, breast cancer; BMI, body mass index.

\section{Results}

General and clinicopathological characterization of the studied patients. The study cohort consisted of 69 newly diagnosed female patients with BC. The mean age \pm SEM of the patients at the time of diagnosis was $52.3 \pm 1.51$ (age range, $29-80$ years). Over half $(50.7 \%)$ were $<50$ years old, of which $29.0 \%$ were between 41 and 50 years old. The mean $\mathrm{BMI} \pm \mathrm{SEM}$ of the patients was $30.0 \pm 0.67 \mathrm{~kg} / \mathrm{m}^{2} ; 52.2 \%$ of the patients were obese at the time of diagnosis and $47.8 \%$ were not obese, with a mean BMI \pm SEM of $33.9 \pm 0.74$ and $25.8 \pm 0.51 \mathrm{~kg} / \mathrm{m}^{2}$, respectively (Table III).

Overall, $84.1 \%$ of the patients were married with three children or less, $46.4 \%$ had experienced a miscarriage and $81.1 \%$ were breastfeeding mothers. The mean age of first pregnancy was $22.7 \pm 0.65$ years. A total of 40 patients had reached menopause at the time of diagnosis, with a mean age \pm SEM 49.9 \pm 0.99 years, while the first appearance of menstruation for most patients was at a mean age \pm SEM of $13.41 \pm 0.19$ years, with only $5.8 \%$ experiencing first menstruation when $<12$ years of age. Most patients did not have any family history of $\mathrm{BC}$ or other cancer types, nor polycystic fibrosis or diabetes mellitus. In total, $92.8 \%$ of the patients were non-smokers, of which $33.3 \%$ performed physical activity. Moreover, most of the patients (75.4\%) did not have diet rich in fat, and a few of the patients (18.8\%) took omega-3 supplements (Table IV).

Regarding the clinicopathological features (Table V), the majority of the patients $(76.8 \%)$ had invasive ductal carcinoma, $7.2 \%$ had invasive lobular carcinoma and $10.1 \%$ were diagnosed with an invasive mixture of ductal and lobular carcinoma. Approximately $56.5 \%$ of the patients had grade II tumors, $53.6 \%$ had tumor size $<2 \mathrm{~cm}$, and $43.5 \%$ had negative lymph node involvement. Based on the hormone receptor phenotypes, $71.0 \%$ of the patients had a luminal BC subtype (ER ${ }^{+} / \mathrm{PR}^{+} / \mathrm{HER}^{-}$): $69.6 \% \mathrm{ER}^{+}, 56.5 \% \mathrm{PR}^{+}$and $59.4 \% \mathrm{HER} 2$ By contrast, HER $2^{+}$was only found in $34.8 \%$ of the patients. Therefore, the $\mathrm{ER}^{+} / \mathrm{PR}^{+} / \mathrm{HER} 2^{-}$phenotype was the most abundant in the patient cohort.

The non-obese and obese $\mathrm{BC}$ groups were significantly different in terms of age and menopausal status $(\mathrm{P}=0.003)$; however, the results did not show any significant differences with regard to other general and clinicopathological characteristics (Tables IV and V). 
Table II. PCR primer sequences for target lncRNAs and reference genes.

\begin{tabular}{|c|c|c|c|c|}
\hline Gene symbol & Gene name & Gene type & Forward primer $\left(5^{\prime}-3^{\prime}\right)$ & Reverse primer $\left(5^{\prime}-3^{\prime}\right)$ \\
\hline GAPDH & $\begin{array}{l}\text { Glyceraldehyde-3- } \\
\text { phosphate dehydrogenase }\end{array}$ & Reference & TCACCAGGGCTGCTTTTAAC & $\begin{array}{l}\text { GATGATCTTGAGGCTGT } \\
\text { TGTCA }\end{array}$ \\
\hline AP001429.1 & lncRNA AP001429.1 & Non-coding & AATATGACTGGGCCCTGCAA & $\begin{array}{l}\text { CCGTTGGCCATTTCGT } \\
\text { GATT }\end{array}$ \\
\hline P5549 & lncRNA P5549 & Non-coding & СTTTTCCGGCTGAGGTGTTC & $\begin{array}{l}\text { TGAACCAGCCATCTCT } \\
\text { CACA }\end{array}$ \\
\hline$P 21015$ & lncRNA P21015 & Non-coding & ACCCCAGAAGTGACAAGAGG & $\begin{array}{l}\text { AGATAAACCGCTGCCT } \\
\text { TGTG }\end{array}$ \\
\hline P19461 & lncRNA P19461 & Non-coding & CAGCCTCCTCCTGTGATGTA & $\begin{array}{l}\text { CGTTCTTCTTGTTTGGA } \\
\text { CCCA }\end{array}$ \\
\hline$B \operatorname{lnc1}$ & lncRNA Blnc1 & Non-coding & ССТТСТССААССАТСТGССТ & $\begin{array}{l}\text { CTCTTCССТСТGCСТC } \\
\text { TGAC }\end{array}$ \\
\hline$S R A 1$ & $\begin{array}{l}\text { lncRNA steroid receptor } \\
\text { RNA activator } 1\end{array}$ & Non-coding & GGAGGATGTGCTGAGACCTT & $\begin{array}{l}\text { CAACTTTCCTCCAGCC } \\
\text { CACT }\end{array}$ \\
\hline$B 4 G A L T 1-A S 1$ & $\begin{array}{l}\text { lncRNA } \\
\text { B4GALT1-AS1 }\end{array}$ & Non-coding & CTAGCCCACCGTCTGTTTTG & $\begin{array}{l}\text { GGAAACTAGCCAACCT } \\
\text { GCAG }\end{array}$ \\
\hline LINCADL & $\begin{array}{l}\text { lincRNA adipogenesis- } \\
\text { and lipogenesis- } \\
\text { associated }\end{array}$ & Non-coding & ATATGACCCAAGACCAGGCC & $\begin{array}{l}\text { TCACAGCGAATCACTC } \\
\text { CCTT }\end{array}$ \\
\hline ANRIL & lncRNA ANRIL & Non-coding & ACGAAGCTCTACACACTTGAAG & $\begin{array}{l}\text { GGATCACAGACCATACT } \\
\text { TGCAC }\end{array}$ \\
\hline$R P 11-20 G 13.3$ & lincRNA RP11-20G13.3 & Non-coding & TCTGGAAGGAGTGTCGGTCT & $\begin{array}{l}\text { CGTGTTCACAGATTGG } \\
\text { GAGA }\end{array}$ \\
\hline LINC00968 & $\begin{array}{l}\text { long intergenic non- } \\
\text { protein coding RNA } 968\end{array}$ & Non-coding & ACCATCCCATTGAGAACCAA & $\begin{array}{l}\text { CGAAAGGCTGGAAGTG } \\
\text { TCAT }\end{array}$ \\
\hline AC011891.5 & lncRNA AC011891.5 & Non-coding & CGAAAGGCTGGAAGTGTCAT & $\begin{array}{l}\text { TGACCCAATTCTGACA } \\
\text { TTTGC }\end{array}$ \\
\hline$G Y G 2 P 1$ & $\begin{array}{l}\text { Glycogenin } 2 \\
\text { pseudogene } 1\end{array}$ & Non-coding & TCAGCCTCCCAAGTAGCTGT & $\begin{array}{l}\text { CAGCCTGTGTCTCCT } \\
\text { CAGTG }\end{array}$ \\
\hline$R P 11-529 H 2.1$ & lincRNA RP11-529H2.1 & Non-coding & AGGAGAATGGTGAAGGCAGA & $\begin{array}{l}\text { TGCCGAAGCAGTTTAA } \\
\text { TCCT }\end{array}$ \\
\hline OLMALINC & $\begin{array}{l}\text { Oligodendrocyte } \\
\text { maturation-associated } \\
\text { lincRNA }\end{array}$ & Non-coding & AGACCCAGGACAGGAGGACT & $\begin{array}{l}\text { ATTGGCAAGATGTTCC } \\
\text { TTGG }\end{array}$ \\
\hline MALAT1 & $\begin{array}{l}\text { Metastasis-associated } \\
\text { lung adenocarcinoma } \\
\text { transcript } 1\end{array}$ & Non-coding & GCAGGGAGAATTGCGTCATT & $\begin{array}{l}\text { TTCTTCGCCTTCCCGT } \\
\text { АCTT }\end{array}$ \\
\hline PCAT6 & $\begin{array}{l}\text { Prostate cancer-associated } \\
\text { ncRNA transcript } 6\end{array}$ & Non-coding & СТCCATCCTCATTCGGTCCA & $\begin{array}{l}\text { GAAGGGTGGTGGTAGA } \\
\text { AGCA }\end{array}$ \\
\hline$U C A 1$ & $\begin{array}{l}\text { Urothelial carcinoma- } \\
\text { associated } 1\end{array}$ & Non-coding & TTTGCCAGCCTCAGCTTAAT & $\begin{array}{l}\text { TTGTCCCCATTTTCCA } \\
\text { TCAT }\end{array}$ \\
\hline MEG3 & Maternally expressed 3 & Non-coding & TCACCTGCTAGCAAACTGGA & $\begin{array}{l}\text { CATGCTCATTCCAGAA } \\
\text { GCCC }\end{array}$ \\
\hline CCAT2 & $\begin{array}{l}\text { Colon cancer-associated } \\
\text { transcript } 2\end{array}$ & Non-coding & ATGAAGGCGTCGTCCAAATG & $\begin{array}{l}\text { TCAGGCAATTGGTCAG } \\
\text { AGGT }\end{array}$ \\
\hline$B C A R 4$ & $\begin{array}{l}\text { BC anti-estrogen } \\
\text { resistance } 4\end{array}$ & Non-coding & CGATGCTTGTCTTGCTCTGA & $\begin{array}{l}\text { CCGCTTTTTCGTATCA } \\
\text { CTCC }\end{array}$ \\
\hline CCAT1 & $\begin{array}{l}\text { Colon cancer-associated } \\
\text { transcript } 1\end{array}$ & Non-coding & TTGCTCACCTTACTGCCTGA & $\begin{array}{l}\text { CCTGCAACTAGACACT } \\
\text { CCCA }\end{array}$ \\
\hline PANDAR & $\begin{array}{l}\text { Promoter of CDKN1A } \\
\text { antisense DNA damage- } \\
\text { activated RNA } 1\end{array}$ & Non-coding & TTGTAGCTCCTCCCATGTCG & $\begin{array}{l}\text { AGGAACAGGCAATGG } \\
\text { GATCA }\end{array}$ \\
\hline
\end{tabular}


Table II. Continued.

\begin{tabular}{|c|c|c|c|c|}
\hline Gene symbol & Gene name & Gene type & Forward primer $\left(5^{\prime}-3^{\prime}\right)$ & Reverse primer $\left(5^{\prime}-3^{\prime}\right)$ \\
\hline HOTAIR & $\begin{array}{l}\text { HOX transcript antisense } \\
\text { RNA }\end{array}$ & Non-coding & GAGTTCCACAGACCAACACC & $\begin{array}{l}\text { AATCCGTTCCATTCCA } \\
\text { CTGC }\end{array}$ \\
\hline NEAT1 & $\begin{array}{l}\text { Nuclear-enriched } \\
\text { abundant transcript } 1\end{array}$ & Non-coding & CCAGTGTGAGTCCTAGCATTGC & $\begin{array}{l}\text { CCTGGAAACAGAACATT } \\
\text { GGAGAAC }\end{array}$ \\
\hline GAS5 & Growth arrest-specific 5 & Non-coding & CCCAAGGAAGGATGAGAATAGC & $\begin{array}{l}\text { CTGTCTAATGCCTGTG } \\
\text { TGCC }\end{array}$ \\
\hline H19 & $\begin{array}{l}\text { H19 imprinted maternally } \\
\text { expressed transcript }\end{array}$ & Non-coding & ATCCGGACACAAAACCCTCT & $\begin{array}{l}\text { AGAGCCGATTCCTGAG } \\
\text { TCAG }\end{array}$ \\
\hline ZFAS1 & ZNFX1 antisense RNA1 & Non-coding & AAGCCACGTGCAGACATCTAC & $\begin{array}{l}\text { CTACTTCCAACACCCGC } \\
\text { ATTCA }\end{array}$ \\
\hline P3134 & lncRNA P3134 & Non-coding & GTGGTGAGATCTCGGGGAAA & $\begin{array}{l}\text { GTGCCAGAATTTCCTC } \\
\text { ACCC }\end{array}$ \\
\hline
\end{tabular}

lncRNA, long non-coding RNAs; lincRNA, long intergenic ncRNA.

Table III. Baseline characteristics of studied patients with BC.

\begin{tabular}{|c|c|c|c|}
\hline Parameters & Total & Non-obese BC & Obese BC \\
\hline Number of patients, $\mathrm{n}(\%)$ & $69(100.0)$ & $33(47.8)$ & $36(52.2)$ \\
\hline Age, years ${ }^{\mathrm{a}}$ & $52.3 \pm 1.51$ & $46.5 \pm 1.55$ & $57.5 \pm 2.20$ \\
\hline $\mathrm{BMI}, \mathrm{kg} / \mathrm{m}^{2 \mathrm{a}}$ & $30.0 \pm 0.67$ & $25.8 \pm 0.51$ & $33.9 \pm 0.74$ \\
\hline Waist circumference, $\mathrm{cm}^{\mathrm{a}}$ & $90.2 \pm 2.84$ & $87.1 \pm 4.56$ & $93.1 \pm 3.48$ \\
\hline Hip circumference, $\mathrm{cm}^{\mathrm{a}}$ & $104.5 \pm 2.94$ & $101.8 \pm 4.51$ & $106.9 \pm 3.84$ \\
\hline $\mathrm{W} / \mathrm{H}$ ratio $^{\mathrm{a}}$ & $0.87 \pm 0.01$ & $0.85 \pm 0.02$ & $0.88 \pm 0.01$ \\
\hline Age of first menstruation, years ${ }^{\mathrm{a}}$ & $13.36 \pm 0.16$ & $13.22 \pm 0.23$ & $13.49 \pm 0.23$ \\
\hline Age since menopause, years ${ }^{\mathrm{a}}$ & $50.30 \pm 0.89$ & $48.37 \pm 1.20$ & $51.43 \pm 1.20$ \\
\hline Age of first pregnancy, years ${ }^{a}$ & $22.37 \pm 0.54$ & $22.10 \pm 0.79$ & $22.62 \pm 0.76$ \\
\hline
\end{tabular}

${ }^{a}$ Data presented as mean \pm SEM. BC, breast cancer; BMI, body mass index; W/H, waist/hip ratio.

Screening of IncRNAs in a selected cohort of obese versus non-obese BC patients. The gene expression levels of the 29 selected lncRNAs were initially measured in a selected cohort of $\mathrm{BC}$ patients, based on the greatest BMI differentiation: 6 obese patients with the highest BMI and 6 non-obese BC patients with the lowest BMI were selected from the overall BC patient cohort. The amplification products for lncRNAs and GAPDH were specific and pure in all samples as assessed by melting curve analysis and across the threshold within 30 cycles.

The expression level of lncRNAs in a selected cohort of obese compared with non-obese patients with $\mathrm{BC}$ is shown in Fig. 1. Among all selected IncRNAs, P5549, P19461, PCAT6, AP001429.1 and P3134 were significantly differentially expressed. The expression levels of circulating PCAT6, $P 19461$ and $P 3134$ were significantly upregulated [fold-change (FC), 2.526 and $\mathrm{P} \leq 0.02$; FC, 1.361 and $\mathrm{P} \leq 0.008$; and FC, 1.5 and $\mathrm{P}=0.05$, respectively], whereas P5549 and AP001429.1 showed a significant decrease in expression within the same group of obese $\mathrm{BC}$ patients (FC, 0.56 and $\mathrm{P}=0.05$; and $\mathrm{FC}, 0.6$ and $\mathrm{P}=0.02$, respectively). The rest of the studied lncRNAs did not show any significant differences in expression between the groups (Fig. 1).

Evaluation of IncRNA expression in a larger cohort of obese and non-obese BC patients. The gene expression levels of the significantly differentially expressed identified lncRNAs, (P5549, P19461, P3134, PCAT6 and AP001429.1) were evaluated in a larger cohort consisting of the study population of 36 obese and 33 non-obese BC patients, as shown in Fig. 2. Among these evaluated IncRNAs, AP001429.1 was significantly downregulated in obese compared with non-obese patients with BC (FC, 0.5; P=0.002). By contrast, P5549 (FC, 1.0; $\mathrm{P}=0.97), P 19461$ (FC, 1.1; $\mathrm{P}=0.56), P 3134$ (FC, 1.2; $\mathrm{P}=0.12$ ) and PCAT6 (FC, 1.0; $\mathrm{P}=0.94)$ were not found to exhibit any significant differences in expression within the larger group of patients (Fig. 2).

To evaluate AP001429.1 as a potential biomarker, a ROC curve was generated using the gene expression values of AP001429.1 in obese and non-obese BC patients. In the 
Table IV. Distribution of general information characteristics of the studied patients with BC.

\begin{tabular}{|c|c|c|c|c|}
\hline Categories & Total, n (\%) & Non-obese BC, n (\%) & Obese BC, n (\%) & P-value \\
\hline Patients & $69(100)$ & $33(47.8)$ & $36(52.2)$ & \\
\hline Age of patients, years & & & & 0.004 \\
\hline$\leq 40$ & $15(21.7)$ & $10(66.7)$ & $5(33.3)$ & \\
\hline $41-60$ & $38(55.1)$ & $21(55.3)$ & $17(44.7)$ & \\
\hline$>60$ & $16(23.2)$ & $2(12.5)$ & $14(87.5)$ & \\
\hline Marital status & & & & 0.56 \\
\hline Single & $7(10.1)$ & $2(28.6)$ & $5(71.4)$ & \\
\hline Married & $58(84.1)$ & $29(50.0)$ & $29(50.0)$ & \\
\hline Divorced & $4(5.8)$ & $2(50.0)$ & $2(50.0)$ & \\
\hline Education level & & & & 0.45 \\
\hline Illiterate & $19(27.5)$ & $7(36.8)$ & $12(63.2)$ & \\
\hline School & $25(36.2)$ & $12(48.0)$ & $13(52.0)$ & \\
\hline First and higher degree & $25(36.2)$ & $14(56.0)$ & $11(44.0)$ & \\
\hline Nationality & & & & 0.57 \\
\hline Saudi & $38(55.1)$ & $17(44.7)$ & $21(55.3)$ & \\
\hline Non-Saudi & $31(44.9)$ & $16(51.6)$ & $15(48.4)$ & \\
\hline Age of first menstruation, years & & & & 0.53 \\
\hline$<12$ & $4(5.8)$ & $3(75.0)$ & $1(25.0)$ & \\
\hline $12-15$ & $61(88.4)$ & $28(45.9)$ & $33(54.1)$ & \\
\hline$>15$ & $4(5.8)$ & $2(50.0)$ & $2(50.0)$ & \\
\hline Menopausal status & & & & 0.003 \\
\hline Postmenopausal & $40(58.0)$ & $13(32.5)$ & $27(67.5)$ & \\
\hline Premenopausal & $29(42.0)$ & $20(69.0)$ & $9(31.0)$ & \\
\hline Age of menopause, years & & & & 0.44 \\
\hline$<48$ & $3(7.5)$ & $0(0.0)$ & $3(100.0)$ & \\
\hline $48-55$ & $32(80.0)$ & $11(34.4)$ & $21(65.6)$ & \\
\hline$>55$ & $5(12.5)$ & $2(40.0)$ & $3(60.0)$ & \\
\hline Hormone replacement therapy & & & & 0.17 \\
\hline Yes & $2(2.9)$ & $0(0.0)$ & $2(100.0)$ & \\
\hline No & $67(97.1)$ & $33(49.3)$ & $34(50.7)$ & \\
\hline Number of children & & & & 0.14 \\
\hline None & $8(11.6)$ & $2(25.0)$ & $6(75.0)$ & \\
\hline$\leq 3$ & $31(44.9)$ & $19(61.3)$ & $12(38.7)$ & \\
\hline $4-6$ & $18(26.1)$ & $6(33.3)$ & $12(66.7)$ & \\
\hline$>6$ & $12(17.4)$ & $6(50.0)$ & $6(50.0)$ & \\
\hline Number of miscarriages & & & & 0.48 \\
\hline None & $27(39.1)$ & $14(51.9)$ & $13(48.1)$ & \\
\hline 1 or 2 & $24(34.8)$ & $13(54.2)$ & $11(45.8)$ & \\
\hline$\geq 3$ & $8(11.6)$ & $2(25.0)$ & $6(75.0)$ & \\
\hline No answer & $10(14.5)$ & $4(40.0)$ & $6(60.0)$ & \\
\hline Age of pregnancy, years & & & & 0.79 \\
\hline$\leq 20$ & $22(36.1)$ & $12(54.5)$ & $10(45.5)$ & \\
\hline $21-30$ & $34(55.7)$ & $16(47.1)$ & $18(52.9)$ & \\
\hline$>30$ & $5(8.2)$ & $3(60.0)$ & $2(40.0)$ & \\
\hline Breast feeding & & & & 0.45 \\
\hline Never & $13(18.8)$ & $5(38.5)$ & $8(61.5)$ & \\
\hline Yes & $56(81.2)$ & $28(50.0)$ & $28(50.0)$ & \\
\hline Family history of BC & & & & 0.89 \\
\hline Yes & $13(18.8)$ & $6(46.2)$ & $7(53.8)$ & \\
\hline No & $56(81.2)$ & $27(48.2)$ & $29(51.8)$ & \\
\hline
\end{tabular}


Table IV. Continued.

\begin{tabular}{|c|c|c|c|c|}
\hline Categories & Total, n (\%) & Non-obese BC, n (\%) & Obese BC, n (\%) & P-value \\
\hline Family history of other cancer & & & & 0.89 \\
\hline Yes & $13(18.8)$ & $6(46.2)$ & $7(53.8)$ & \\
\hline No & $56(81.2)$ & $27(48.2)$ & $29(51.8)$ & \\
\hline Polycystic fibrosis status & & & & 0.35 \\
\hline Yes & $9(13.0)$ & $3(33.3)$ & $6(66.7)$ & \\
\hline No & $60(87.0)$ & $30(50.0)$ & $30(50.0)$ & \\
\hline Diabetes mellitus status & & & & 0.92 \\
\hline Yes & $15(21.7)$ & $7(46.7)$ & $8(53.3)$ & \\
\hline No & $54(78.3)$ & $26(48.1)$ & $28(51.9)$ & \\
\hline Physical activities performance & & & & 0.31 \\
\hline Yes & $23(33.3)$ & $13(56.5)$ & $10(43.5)$ & \\
\hline No & $46(66.7)$ & $20(43.5)$ & $26(56.5)$ & \\
\hline Smoking status & & & & 0.2 \\
\hline Yes & $5(7.2)$ & $1(20.0)$ & $4(80.0)$ & \\
\hline No & $64(92.8)$ & $32(50.0)$ & $32(50.0)$ & \\
\hline Omega-3 supplements & & & & 0.17 \\
\hline Yes & $13(18.8)$ & $4(30.8)$ & $9(69.2)$ & \\
\hline No & $56(81.2)$ & $29(51.8)$ & $27(48.2)$ & \\
\hline Diet rich in fat & & & & 0.23 \\
\hline Yes & $17(24.6)$ & $6(35.3)$ & $11(64.7)$ & \\
\hline No & $52(75.4)$ & $27(51.9)$ & $25(48.1)$ & \\
\hline
\end{tabular}

$\mathrm{BC}$, breast cancer.

ROC curve analysis (Fig. 3 and Table SI), the area under the ROC curve was 0.684 (nearly 0.7), indicating that AP001429.1 expression enabled weak but significant differentiation of patients with $\mathrm{BC}$ based on obesity status $(\mathrm{P}=0.004)(58)$. Therefore, AP001429.1 may act as a potential biomarker in obese patients with $\mathrm{BC}$.

Association between AP001429.1 expression level and patient baseline characteristics. Differential expression patterns in AP001429.1 were observed when assessing the association with patient baseline features (Table SII). Significant differences in AP001429.1 expression with regard to patient baseline characteristics were assessed by Bonferroni's correction $(\mathrm{P} \leq 0.05)$ and are presented in Fig. 4. Significant decreases in AP001429.1 expression were detected in obese patients with $\mathrm{BC}$ who were at middle-aged ( $\mathrm{FC}, 0.4 ; \mathrm{P}=0.03$ ), married ( $\mathrm{FC}, 0.4 ; \mathrm{P}=0.006$ ), Saudi national (FC, $0.5 ; \mathrm{P}=0.02$ ) and patients who had low education level (FC, 0.2; $\mathrm{P}<0.0003)$. AP001429.1 also showed significant downregulation in relation to premenopausal obese $\mathrm{BC}$ patients ( $\mathrm{FC}, 0.3 ; \mathrm{P}=0.002)$, in those who were breastfeeding their children $(\mathrm{FC}, 0.4 ; \mathrm{P}<0.001)$ and in those who experienced their first menstruation event between 12 and 15 years old (FC, $0.5 ; \mathrm{P}=0.01$ ) or had their first pregnancy aged between 21 and 30 (FC, 0.4; $\mathrm{P}=0.03$ ). Moreover, the non-smoking obese $\mathrm{BC}$ patients, those who did not take omega-3 supplements and those who performed physical activity also showed a significantly decreased expression level of AP001429.1 (FC, 0.6 and $\mathrm{P}=0.01$;
FC, 0.5 and $\mathrm{P}=0.02$; and $\mathrm{FC}, 0.2$ and $\mathrm{P}<0.001$, respectively). Furthermore, AP001429.1 showed significant downregulation in relation to diabetic obese patients with $\mathrm{BC}$, as well as those who did not have hormone replacement therapy, those who did not have any family history of $\mathrm{BC}$, other cancer types or polycystic fibrosis (FC, 0.2 and $\mathrm{P}<0.001 ; \mathrm{FC}, 0.5$ and $\mathrm{P}=0.01 ; \mathrm{FC}, 0.4$ and $\mathrm{P}=0.004$; and $\mathrm{FC}, 0.5$ and $\mathrm{P}=0.01$, respectively). Moreover, the significantly decreased expression of AP001429.1 was also detected in obese patients with $\mathrm{BC}$ who had 4 to 6 children $(\mathrm{FC}, 0.2 ; \mathrm{P}=0.03)$ and those who had miscarriages once or twice (FC, $0.4 ; \mathrm{P}=0.03$ ) (Fig. 4).

Association between AP001429.1 expression level and patient clinicopathological characteristics. Associations in the expression levels of AP001429.1 in obese patients with $\mathrm{BC}$ compared with that in non-obese patients with $\mathrm{BC}$ were assessed with regard to patient clinicopathological characteristics (Table SIII). Significant differences in AP001429.1 expression with regard to patient clinicopathological characteristics were assessed by Bonferroni's correction $(\mathrm{P} \leq 0.05)$ and are presented in Fig. 5. AP001429.1 exhibited a significantly lower expression level in obese patients compared with that in non-obese patients with $\mathrm{BC}$; however, the significantly decreased expression was detected with regard to negative HER2 status (FC, 0.4; $\mathrm{P}=0.02$ ), negative E-cadherin expression (FC, 0.1; $\mathrm{P}<0.001)$, negative vascular invasion ( $\mathrm{FC}, 0.4$; $\mathrm{P}=0.004)$, negative margin invasion $(\mathrm{FC}, 0.5 ; \mathrm{P}=0.02)$ and 
Table V. Distribution of clinicopathological features of the studied patients with BC.

\begin{tabular}{|c|c|c|c|c|}
\hline Categories & Total, n (\%) & Non-obese BC, n (\%) & Obese BC, n (\%) & P-value \\
\hline Patients & $69(100)$ & $33(47.8)$ & $36(52.2)$ & \\
\hline Hormone receptor phenotype & & & & 0.28 \\
\hline Luminal & $49(71.0)$ & $25(51.0)$ & $24(49.0)$ & \\
\hline HER2-enriched & $10(14.5)$ & $5(50.0)$ & $5(50.0)$ & \\
\hline Triple negative/basal like & $6(8.7)$ & $1(16.7)$ & $5(83.3)$ & \\
\hline Unknown & $4(5.8)$ & $2(50.0)$ & $2(50.0)$ & \\
\hline ER status & & & & 0.53 \\
\hline $\mathrm{ER}^{-}$ & $17(24.6)$ & $7(41.2)$ & $10(58.8)$ & \\
\hline $\mathrm{ER}^{+}$ & $48(69.6)$ & $24(50.0)$ & $24(50.0)$ & \\
\hline Unknown & $4(5.8)$ & $2(50.0)$ & $2(50.0)$ & \\
\hline PR status & & & & 0.08 \\
\hline $\mathrm{PR}^{-}$ & $26(37.7)$ & $9(34.6)$ & $17(65.4)$ & \\
\hline $\mathrm{PR}+$ & $39(56.5)$ & $22(56.4)$ & $17(43.6)$ & \\
\hline Unknown & $4(5.8)$ & $2(50.0)$ & $2(50.0)$ & \\
\hline HER2 status & & & & 0.19 \\
\hline HER2- & $41(59.4)$ & $17(41.5)$ & $24(58.5)$ & \\
\hline $\mathrm{HER}^{+}{ }^{+}$ & $24(34.8)$ & $14(58.3)$ & $10(41.7)$ & \\
\hline Unknown & $4(5.8)$ & $2(50.0)$ & $2(50.0)$ & \\
\hline Lymph node involvement & & & & 0.67 \\
\hline Negative & $30(43.5)$ & $12(40.0)$ & $18(60.0)$ & \\
\hline Positive & $15(21.7)$ & $7(46.7)$ & $8(53.3)$ & \\
\hline Unknown & $24(34.8)$ & $14(58.3)$ & $10(41.7)$ & \\
\hline Size of tumor, $\mathrm{cm}$ & & & & 0.69 \\
\hline$<2$ & $37(53.6)$ & $17(45.9)$ & $20(54.1)$ & \\
\hline $2-5$ & $22(31.9)$ & $9(40.9)$ & $13(59.1)$ & \\
\hline$>5$ & $3(4.3)$ & $2(66.7)$ & $1(33.3)$ & \\
\hline Unknown & $7(10.1)$ & $5(71.4)$ & $2(28.6)$ & \\
\hline Tumor grade & & & & 0.37 \\
\hline I & $8(11.6)$ & $4(50.0)$ & $4(50.0)$ & \\
\hline II & $39(56.5)$ & $16(41.0)$ & $23(59.0)$ & \\
\hline III & $18(26.1)$ & $11(61.1)$ & $7(38.9)$ & \\
\hline Unknown & $4(5.8)$ & $2(50.0)$ & $2(50.0)$ & \\
\hline Histotype & & & & 0.32 \\
\hline DCIS & $53(76.8)$ & $23(43.4)$ & $30(56.6)$ & \\
\hline LCIS & $5(7.2)$ & $3(60.0)$ & $2(40.0)$ & \\
\hline Mixture of ductal and lobular & $7(10.1)$ & $5(71.4)$ & $2(28.6)$ & \\
\hline Unknown & $4(5.8)$ & $2(50.0)$ & $2(50.0)$ & \\
\hline Vascular invasion & & & & 0.28 \\
\hline Negative & $42(60.9)$ & $19(45.2)$ & $23(54.8)$ & \\
\hline Positive & $11(15.9)$ & $3(27.3)$ & $8(72.7)$ & \\
\hline Unknown & $16(23.2)$ & $11(68.8)$ & $5(31.3)$ & \\
\hline Margin & & & & 0.40 \\
\hline Negative & $41(59.4)$ & $17(41.5)$ & $24(58.5)$ & \\
\hline Positive & $1(3.6)$ & $0(0.0)$ & $1(100.0)$ & \\
\hline Unknown & $27(39.1)$ & $16(59.3)$ & $11(40.7)$ & \\
\hline
\end{tabular}

BC, breast cancer; DCIS, ductal carcinoma in situ; ER, estrogen receptor; HER2, human epidermal growth factor receptor 2; LCIS, lobular carcinoma in situ; PR, progesterone receptor.

LCIS (FC, 0.2; P<0.001) BC patients. By contrast, a high expression level of AP001429.1 was only detected in relation to positive E-cadherin expression $(\mathrm{FC}, 5.3 ; \mathrm{P}=0.04)$ within the obese patients with BC (Fig. 5).

\section{Discussion}

lncRNA, as a class of untranslated regulatory RNA, is considered an important type of cellular RNA that plays a critical 


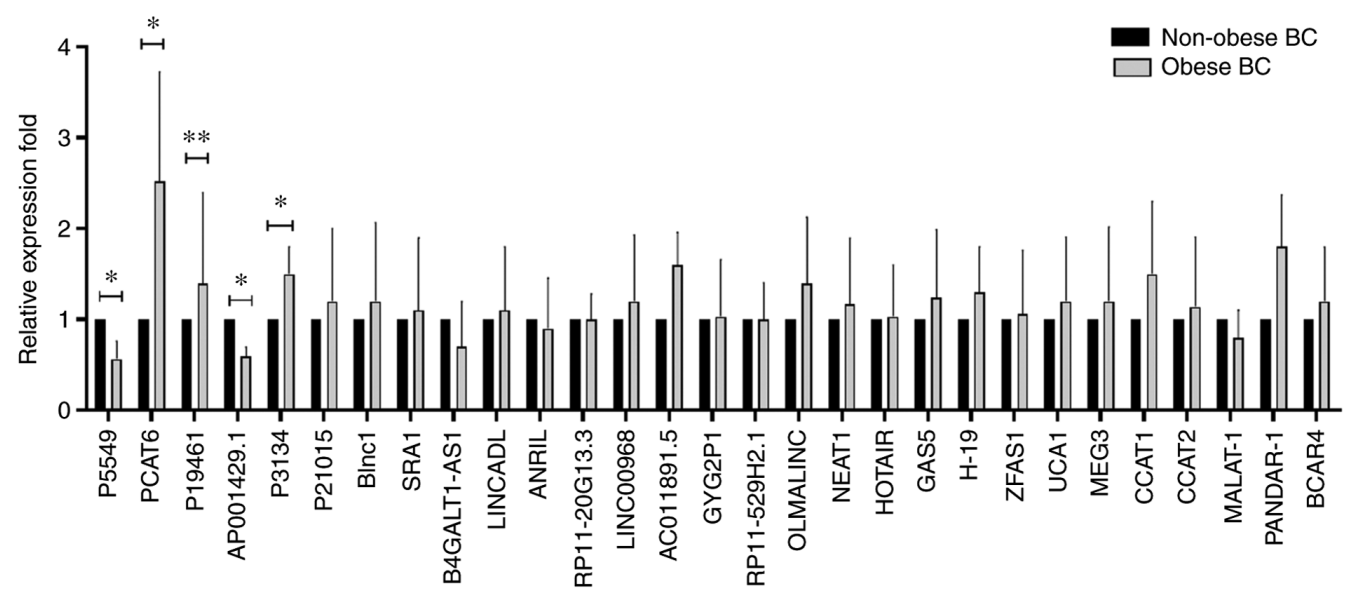

Figure 1. Relative expression fold of long non-coding RNAs in a selected cohort of obese compared with non-obese patients with BC. Gene expression was detected by reverse transcription-quantitative PCR and normalized according to GAPDH expression. Error bars represent $\mathrm{SEM}$. $\mathrm{P} \leq 0.05$ and ${ }^{* *} \mathrm{P}<0.01$. $\mathrm{BC}$, breast cancer.
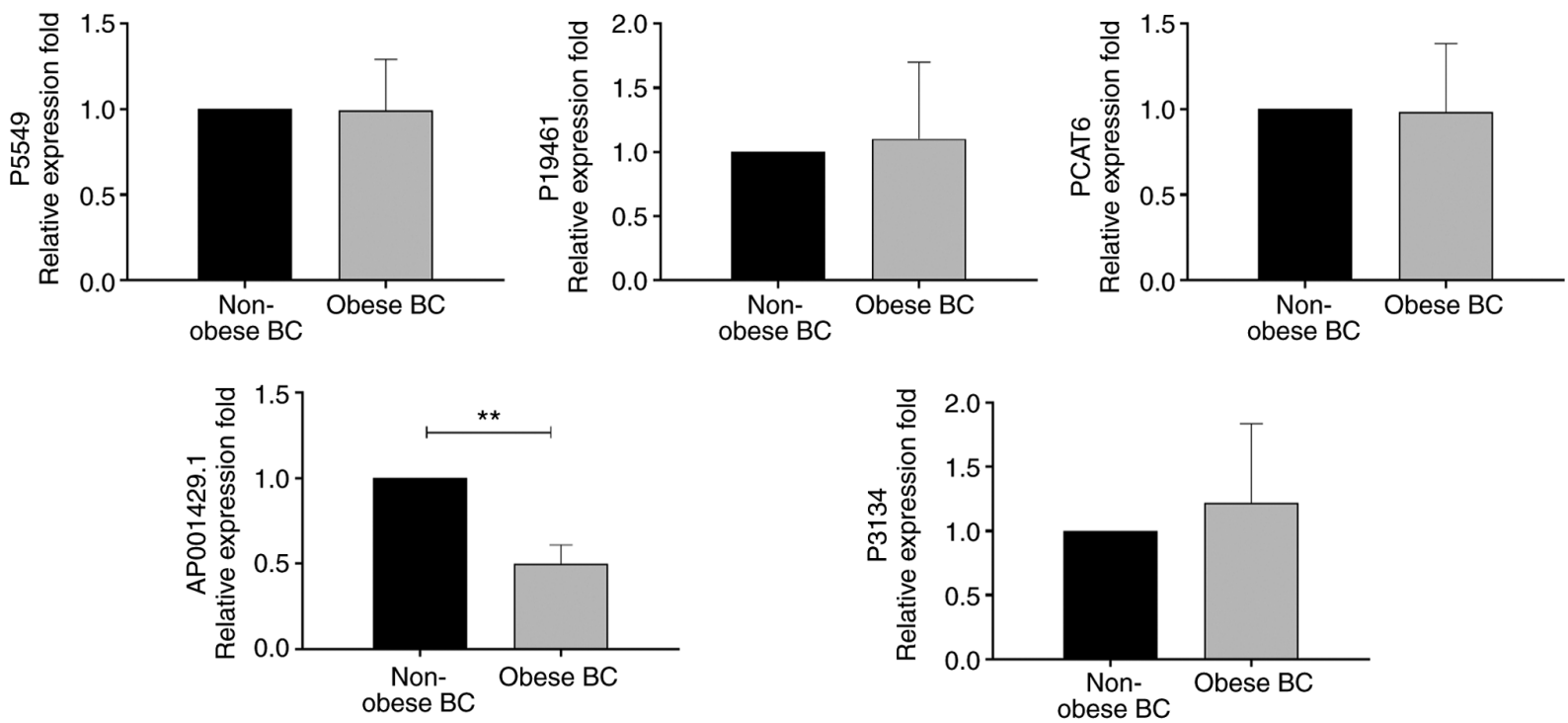

Figure 2. Long non-coding RNA relative expression fold in a larger cohort of obese compared with non-obese patients with BC. Gene expression was detected by reverse transcription-quantitative PCR and normalized according to GAPDH expression. Error bars represent SEM. ${ }^{* *} \mathrm{P}<0.01$. BC, breast cancer.

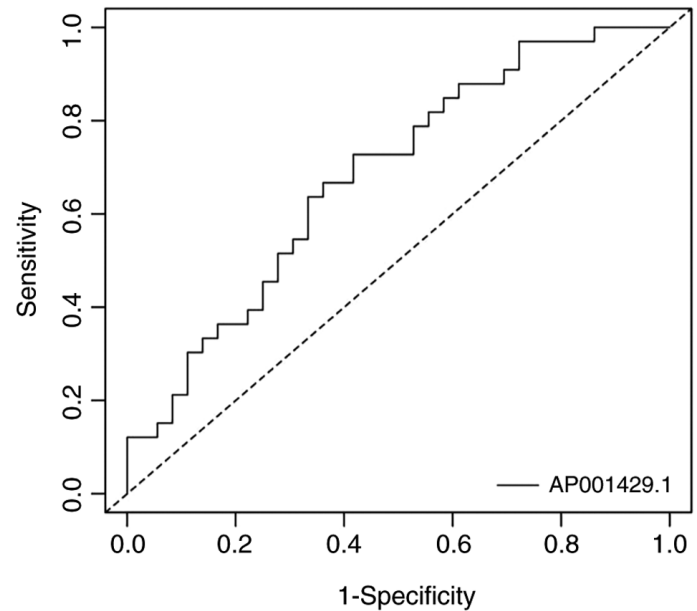

Figure 3. Receiver operating characteristic curve for the gene expression of AP001429.1, a suggested potential biomarker in obese patients with breast cancer. regulatory role in a number of biological processes in normal development, as well as in tumorigenesis and tumor progression processes (59). IncRNA is regarded as a key regulator of diseases with tissue specificity (60). IncRNA controls the flux of genetic information modulating various cellular processes, such as modulation of chromosome structure, transcription, splicing, mRNA stability and availability, post-translational modifications (61) and epigenetic mechanisms (62). Obesity involves profound epigenetic changes and affects the expression of obesity-associated lncRNAs that may be involved in cancer initiation and/or progression and affect cancer therapy. To the best of our knowledge, the approach of the present study comparing differences between obese and non-obese patients with BC has so far not been applied. Previous studies investigated healthy non-obese versus obese patients $(15,16,44,63,64)$ as well as healthy control cases versus patients with BC (65-68). Therefore, in the present study, IncRNA expression levels were evaluated in whole blood taken from BC patients by liquid 



Figure 4. Relative expression fold of AP001429.1 and its association with patient baseline characteristics within obese patients with BC compared with the same categories in non-obese patients with BC. Gene expression was detected by reverse transcription-quantitative-PCR and normalized according to GAPDH expression. Error bars represent SEM. The significance level is presented as assessed by Bonferroni's correction. ${ }^{*} \mathrm{P} \leq 0.05,{ }^{* * *} \mathrm{P}<0.01$ and ${ }^{* * * *} \mathrm{P}<0.001$. BC, breast cancer. 

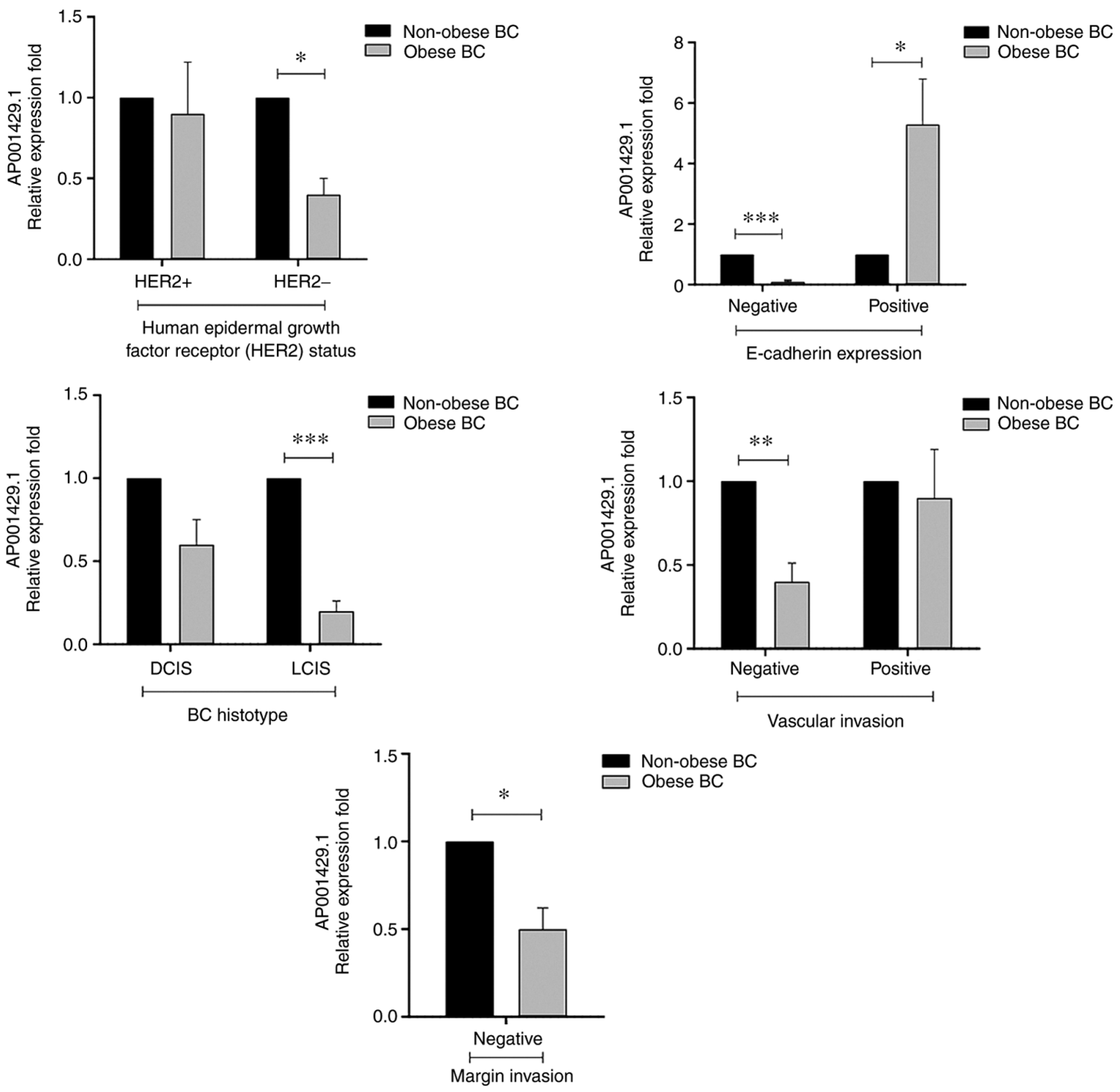

Figure 5. Relative expression fold of AP001429.1 and its association with patient clinicopathological parameters in obese patients with BC compared with the same categories in non-obese patients with BC. Gene expression was detected by reverse transcription-quantitative PCR and normalized according to GAPDH expression. Error bars represent SEM. The significance level is presented as assessed by Bonferroni's correction. ${ }^{*} \mathrm{P} \leq 0.05,{ }^{* * *} \mathrm{P}<0.01$ and ${ }^{* * * *} \mathrm{P}<0.001$. BC, breast cancer; DCIS, ductal carcinoma in situ; LCIS, lobular carcinoma in situ.

biopsy, with obese patients being compared with non-obese patients, aiming to determine the expression status of lncRNAs in obese patients with $\mathrm{BC}$ and their associations with the general and clinicopathological attributes of the patients.

AP001429.1 is also known as novel transcript sense intronic lncRNA to tetratricopeptide repeat domain 3; it is located on the long arm of chromosome 21 (21q22.13) and is 530 nucleotides in length (69). Very limited information is available on the expression and biological functions of AP001429.1; however, its mRNA expression has been detected in a number of normal human tissues and cells, including whole blood, brain, cerebellum, endometrium, heart, ovary and testis (69). Furthermore, according to the RNAcentral resource (70) and the LncBase database (71), AP001429.1 is targeted by several miRNAs; notably, a number of AP001429.1-targeted miRNAs are downregulated and reported to have roles as tumor suppressors in BC, such as $m i R-124-3 p$ (72), $m i R-196 b-5 p$ (73), the miR-34-5p family (74,75), miR-449b-5p (76), miR-940 (77) and $m i R-99 a-3 p(78,79)$. In addition, $m i R-196 a-5 p$ and $m i R-449 a$ were upregulated and reported to be involved in oncogenesis in BC $(80,81)$, suggesting that AP001429.1 may function as a potential tumor suppressor in BC by targeting those miRNAs. The present study showed that AP001429.1 was significantly downregulated in obese patients with BC compared with non-obese patients with BC. A significant decrease in AP001429.1 expression was detected in obese patients with BC who were middle-aged, premenopausal, married, had 4 to 6 children and who breastfed their newborn. Moreover, in the BC patient cohort, non-smoking status, performance of a physical activity, diabetes, the absence of hormone replacement therapy and the absence of a family history of cancer or polycystic fibrosis, was also associated with a significant decrease in the expression level of AP001429.1 (Fig. 3 and Table SII). Moreover, a significant association was also detected with regard to certain molecular and histological characteristic, including negative HER2 status, negative E-cadherin expression, negative vascular and margin invasion, and LCIS. Obese patients with BC also 
exhibited downregulation of AP001429.1 compared with non-obese patients with BC (Fig. 4 and Table SIII). The exact reasoning behind the significant associations with regard to these parameters is not clear.

Numerous lncRNAs have been detected as differentially expressed in different cells and tissues associated with cancer and/or obesity (82). Moreover, the differential expression of IncRNAs may contribute to the initiation, development, invasion and metastasis of various types of cancer, including BC, as well as obesity development, brown adipocyte differentiation and the function of adipose tissue (83), through both activation and inhibition of the expression of other genes (84) that could affect various cancer-related physiological processes (85). Therefore, lncRNAs may serve as BC prognostic and diagnostic biomarkers as well as being useful as therapeutic targets for BC treatments. Despite the existence of studies considering lncRNAs in BC, there is still an urgent need for more studies focusing on the role of IncRNAs in BC with obesity in order to provide a better understanding of their involvement and offer new insights into the role of lncRNAs in obesity-related BC.

In conclusion, the present results demonstrated the downregulation of AP001429.1 in obese patients with BC, suggesting that obesity may have a role in inhibiting the expression of AP001429.1, which could be considered as a potential tumor suppressor of $\mathrm{BC}$. This information may help improve our understanding and provide an important research tool with regard to the molecular associations between obesity and BC. Therefore, the expression of AP001429.1 could serve as a potential biomarker for $\mathrm{BC}$ prognosis and a target for therapy. Further study is needed to confirm these findings and elucidate the underlying mechanism for the effects of AP001429.1 with regard to connections between obesity and $\mathrm{BC}$.

The current study has certain limitations, including the small sample size, which needs to be increased to confirm and validate the findings. Further control cross-sectional studies using healthy obese and non-obese patients with an increase in sample size will be conducted in the near future. Finally, further investigation is required to elucidate the expression profile and functional role of AP001429.1 in BC tissue.

\section{Acknowledgements}

Not applicable.

\section{Funding}

This project was funded by the Deanship of Scientific Research (DSR) at King Abdulaziz University (KAU) Jeddah, Kingdom of Saudi Arabia (grant no. G: 638/130/1438).

\section{Availability of data and materials}

The datasets used and/or analyzed during the current study are available from the corresponding author on reasonable request.

\section{Authors' contributions}

MAH, HC, KAAS and ALAM designed and coordinated the experiments. KAAS obtained the ethical approval, patients' consent and blood samples. MAH performed the experiments and analyzed the data. HC contributed to laboratory facilitates and project funding. MAH wrote the original manuscript draft. KAAS and $\mathrm{HC}$ edited the manuscript. $\mathrm{HC}, \mathrm{MAH}$ and KAAS confirm the authenticity of all the raw data. All authors read and approved the final manuscript.

\section{Ethics approval and consent to participate}

This study was approved by the Unit of Biomedical Ethics Research Committee, KAUH (approval no. HA-02-J-008). All patients signed a consent form to engage in this study.

\section{Patient consent for publication}

Not applicable.

\section{Competing interests}

The authors declare no that they have no competing interests.

\section{References}

1. Bray F, Ferlay J, Soerjomataram I, Siegel RL, Torre LA and Jemal A: Global cancer statistics 2018: GLOBOCAN estimates of incidence and mortality worldwide for 36 cancers in 185 countries. CA Cancer J Clin 68: 394-424, 2018.

2. Smith KB and Smith MS: Obesity statistics. Prim Care 43: 121-135, 2016.

3. WHO: Obesity and overweight. https://www.who.int/en/newsroom/fact-sheets/detail/obesity-and-overweight. Accessed December 15, 2020.

4. Memish ZA, El Bcheraoui C, Tuffaha M, Robinson M, Daoud F, Jaber S, Mikhitarian S, Al Saeedi M, AlMazroa MA, Mokdad AH and Al Rabeeah AA: Obesity and associated factors-Kingdom of Saudi Arabia, 2013. Prev Chronic Dis 11: E174, 2014.

5. De Pergola G and Silvestris F: Obesity as a major risk factor for cancer. J Obes 2013: 291546, 2013.

6. Argolo DF, Hudis CA and Iyengar NM: The impact of obesity on breast cancer. Curr Oncol Rep 20: 47, 2018.

7. Iyengar NM, Hudis CA and Dannenberg AJ: Obesity and cancer: Local and systemic mechanisms. Annu Rev Med 66: 297-309, 2015.

8. Chan DS and Norat T: Obesity and breast cancer: Not only a risk factor of the disease. Curr Treat Options Oncol 16: 22, 2015.

9. Wang J, Zhang X, Chen W, Hu X, Li J and Liu C: Regulatory roles of long noncoding RNAs implicated in cancer hallmarks. Int J Cancer 146: 906-916, 2020.

10. Zhao H, Shi J, Zhang Y, Xie A, Yu L, Zhang C, Lei J, Xu H, Leng Z, Li T, et al: LncTarD: A manually-curated database of experimentally-supported functional lncRNA-target regulations in human diseases. Nucleic Acids Res 48: D118-D126, 2019.

11. Li Z, Zhao W, Wang M and Zhou X: The Role of Long Noncoding RNAs in Gene Expression Regulation. In: Gene Expression Profiling in Cancer IntechOpen, London, UK, 2019.

12. Zhuang C, Ma Q, Zhuang C, Ye J, Zhang F and Gui Y: LncRNA GClnc1 promotes proliferation and invasion of bladder cancer through activation of MYC. FASEB J 33: 11045-11059, 2019.

13. Li Y, Yang X, Kang X and Liu S: The regulatory roles of long noncoding RNAs in the biological behavior of pancreatic cancer. Saudi J Gastroenterol 25: 145-151, 2019.

14. Rohde K, KellerM, la CourPoulsen L, Blüher M, Kovacs P and Böttcher Y: Genetics and epigenetics in obesity. Metabolism 92: 37-50, 2019.

15. Sun J, Ruan Y, Wang M, Chen R, Yu N, Sun L, Liu T and Chen H: Differentially expressed circulating LncRNAs and mRNA identified by microarray analysis in obese patients. Sci Rep 6: 35421, 2016.

16. Yau MY, Xu L, Huang CL and Wong CM: Long non-coding RNAs in obesity-induced cancer. Noncoding RNA 4: 19, 2018.

17. Zeng J, Sauter ER and Li B: FABP4: A new player in obesityassociated breast cancer. Trends Mol Med 26: 437-440, 2020

18. Liu Y, Ji Y, Li M, Wang M, Yi X, Yin C, Wang S, Zhang M, Zhao $Z$ and Xiao $Y$ : Integrated analysis of long noncoding RNA and mRNA expression profile in children with obesity by microarray analysis. Sci Rep 8: 8750, 2018. 
19. Zhang Y, Fang ZX, Guo X, Dong H, Zhou K, Huang Z and Xiao Z: IncRNA B4GALT1-AS1 promotes colon cancer cell stemness and migration by recruiting YAP to the nucleus and enhancing YAP transcriptional activity. J Cell Physiol 234: 18524-18534, 2019.

20. Ouyang S, Zhou X, Chen Z, Wang M, Zheng X and Xie M: LncRNA BCAR4, targeting to miR-665/STAT3 signaling, maintains cancer stem cells stemness and promotes tumorigenicity in colorectal cancer. Cancer Cell Int 19: 72, 2019.

21. Mi L, Zhao XY, Li S, Yang G and Lin JD: Conserved function of the long noncoding RNA Blncl in brown adipocyte differentiation. Mol Metab 6: 101-110, 2016.

22. Sun L and Lin JD: Function and mechanism of long noncoding RNAs in adipocyte biology. Diabetes 68: 887-896, 2019.

23. Li GH, Ma ZH and Wang X: Long non-coding RNA CCAT1 is a prognostic biomarker for the progression of oral squamous cell carcinoma via miR-181a-mediated Wnt/ $\beta$-catenin signaling pathway. Cell Cycle 18: 2902-2913, 2019.

24. Hu M, Zhang Q, Tian XH, Wang JL, Niu YX and Li G: lncRNA CCAT1 is a biomarker for the proliferation and drug resistance of esophageal cancer via the miR-143/PLK1/BUBR1 axis. Mol Carcinog 58: 2207-2217, 2019.

25. Li Y, Zhu G, Ma Y and Qu H: IncRNA CCAT1 contributes to the growth and invasion of gastric cancer via targeting miR-219-1. J Cell Biochem 120: 19457-19468, 2019.

26. Cai Y, He J and Zhang D: Long noncoding RNA CCAT2 promotes breast tumor growth by regulating the Wnt signaling pathway. Onco Targets Ther 8: 2657-2664, 2015.

27. Schmidt E, Dhaouadi I, Gaziano I, Oliverio M, Klemm P, Awazawa M, Mitterer G, Fernandez-Rebollo E, Pradas-Juni M, Wagner W, et al: LincRNA H19 protects from dietary obesity by constraining expression of monoallelic genes in brown fat. Nat Commun 9: 3622, 2018

28. Zhang X, Xue CY, Line J, Ferguson JF, Weiner A, Liu W, Han Y, Hinkle C, Li W, Jiang H, et al: Interrogation of nonconserved human adipose lincRNAs identifies a regulatory role of linc-ADAL in adipocyte metabolism. Sci Transl Med 10: eaar5987, 2018.

29. Kong X, Wang J, Cao Y, Zhang H, Lu X, Wang Y, Bo C, Wang T, Li S, Tian K, et al: The long noncoding RNA MALAT-1 functions as a competing endogenous RNA to regulate MSL2 expression by sponging miR-338-3p in myasthenia gravis. J Cell Biochem 120: 5542-5550, 2019.

30. Han X, Xu Z, Tian G, Tang Z, Gao J, Wei Y and Xu X: Suppression of the long non-coding RNA MALAT-1 impairs the growth and migration of human tongue squamous cell carcinoma SCC4 cells. Arch Med Sci 15: 992-1000, 2019.

31. Tripathi V, Ellis JD, Shen Z, Song DY, Pan Q, Watt AT, Freier SM Bennett CF, Sharma A, Bubulya PA, et al: The nuclear-retained noncoding RNA MALAT1 regulates alternative splicing by modulating SR splicing factor phosphorylation. Mol Cell 39: 925-938, 2010

32. Gernapudi R, Wolfson B, Zhang Y, Yao Y, Yang P, Asahara H and Zhou Q: MicroRNA 140 promotes expression of long noncoding RNA NEAT1 in adipogenesis. Mol Cell Biol 36: 30-38, 2015

33. Cooper DR, Carter G, Li P, Patel R, Watson JE and Patel NA: Long non-coding RNA NEAT1 associates with SRp40 to temporally regulate PPAR $\gamma 2$ splicing during adipogenesis in 3T3-L1 cells. Genes (Basel) 5: 1050-1063, 2014.

34. Li Y, Su X and Pan H: Inhibition of lncRNA PANDAR reduces cell proliferation, cell invasion and suppresses EMT pathway in breast cancer. Cancer Biomark 25: 185-192, 2019.

35. Liu J, Ben Q, Lu E, He X, Yang X, Ma J, Zhang W, Wang Z, Liu T, Zhang $J$ and Wang $H$ : Long noncoding RNA PANDAR blocks CDKN1A gene transcription by competitive interaction with p53 protein in gastric cancer. Cell Death Dis 9: 168, 2018.

36. Wang H, Fang L, Jiang J, Kuang Y, Wang B, Shang X, Han P, Li Y, Liu M, Zhang Z and Li P: The cisplatin-induced lncRNA PANDAR dictates the chemoresistance of ovarian cancer via regulating SFRS2-mediated p53 phosphorylation. Cell Death Dis 9: 1103, 2018

37. Xin Y, He X, Zhao W, Zhan M, Li Y, Xiao J, He K and Lu L: LncRNA PCAT6 increased cholangiocarcinoma cell proliferation and invasion via modulating miR-330-5p. Am J Transl Res 11: 6185-6195, 2019.

38. Wu H, Zou Q, He H, Liang Y, Lei M, Zhou Q, Fan D and Shen L: Long non-coding RNA PCAT6 targets miR-204 to modulate the chemoresistance of colorectal cancer cells to 5-fluorouracil-based treatment through HMGA2 signaling Cancer Med 8: 2484-2495, 2019.
39. Huang WM, Su G, Huang XX, Zou A, Wu J, Yang Y, Zhu Y, Liang S, Li D, Ma F and Guo L: Long noncoding RNA PCAT6 inhibits colon cancer cell apoptosis by regulating anti-apoptotic protein ARC expression via EZH2. Cell Cycle 18: 69-83, 2019.

40. Dong F, Ruan S, Wang J, Xia Y, Le K, Xiao X, Hu T and Wang Q: M2 macrophage-induced lncRNA PCAT6 facilitates tumorigenesis and angiogenesis of triple-negative breast cancer through modulation of VEGFR2. Cell Death Dis 11: 728, 2020.

41. Tong H, Zhuang X, Cai J, Ding Y, Si Y, Zhang H and Shen M: Long noncoding RNA ZFAS1 promotes progression of papillary thyroid carcinoma by sponging miR-590-3p and upregulating HMGA2 expression. Onco Targets Ther 12: 7501-7512, 2019.

42. Dong D, Mu Z, Wei N, Sun M, Wang W, Xin N, Shao Y and Zhao C: Long non-coding RNA ZFAS1 promotes proliferation and metastasis of clear cell renal cell carcinoma via targeting miR-10a/SKA1 pathway. Biomed Pharmacother 111: 917-925, 2019.

43. Hassan MA, Al-Sakkaf K, Shait Mohammed MR, Dallol A, Al-Maghrabi J, Aldahlawi A, Ashoor S, Maamra M, Ragoussis J, $\mathrm{Wu} \mathrm{W}$, et al: Integration of transcriptome and metabolome provides unique insights to pathways associated with obese breast cancer patients. Front Oncol 10: 804, 2020.

44. Mansoori Y, Tabei MB, Askari A, Izadi P, Daraei A, Bastami M, Naghizadeh MM, Nariman-Saleh-Fam Z, Mansoori B and Tavakkoly-Bazzaz J: Expression levels of breast cancer-related GAS5 and LSINCT5 lncRNAs in cancer-free breast tissue: Molecular associations with age at menarche and obesity. Breast J 24: 876-882, 2018

45. Ni W, Yao S, Zhou Y, Liu Y, Huang P, Zhou A, Liu J, Che L and Li J: Long noncoding RNA GAS5 inhibits progression of colorectal cancer by interacting with and triggering YAP phosphorylation and degradation and is negatively regulated by the $\mathrm{m}^{6} \mathrm{~A}$ reader YTHDF3. Mol Cancer 18: 143, 2019.

46. Ji J, Dai X, Yeung SJ and He X: The role of long non-coding RNA GAS5 in cancers. Cancer Manag Res 11: 2729-2737, 2019.

47. Sun M, Jin FY, Xia R, Kong R, Li JH, Xu TP, Liu YW, Zhang EB, Liu XH and De W: Decreased expression of long noncoding RNA GAS5 indicates a poor prognosis and promotes cell proliferation in gastric cancer. BMC Cancer 14: 319, 2014.

48. Li Z, Jin C, Chen S, Zheng Y, Huang Y, Jia L, Ge W and Zhou Y: Long non-coding RNA MEG3 inhibits adipogenesis and promotes osteogenesis of human adipose-derived mesenchymal stem cells via miR-140-5p. Mol Cell Biochem 433: 51-60, 2017.

49. Xu B, Gerin I, Miao H, Vu-Phan D, Johnson CN, Xu R, Chen XW, Cawthorn WP, MacDougald OA and Koenig RJ: Multiple roles for the non-coding RNA SRA in regulation of adipogenesis and insulin sensitivity. PLoS One 5: e14199, 2010.

50. Gong P, Qiao F, Wu H, Cui H, Li Y, Zheng Y, Zhou M and Fan H: LncRNA UCA1 promotes tumor metastasis by inducing miR-203/ZEB2 axis in gastric cancer. Cell Death Dis 9: 1158, 2018.

51. Bian Z, Jin L, Zhang J, Yin Y, Quan C, Hu Y, Feng Y, Liu H, Fei B, Mao Y, et al: LncRNA-UCA1 enhances cell proliferation and 5-fluorouracil resistance in colorectal cancer by inhibiting miR-204-5p. Sci Rep 6: 23892, 2016

52. Yao F, Wang Q and Wu Q: The prognostic value and mechanisms of lncRNA UCA1 in human cancer. Cancer Manag Res 11: 7685-7696, 2019.

53. de Onis M and Habicht JP: Anthropometric reference data for international use: Recommendations from a world health organization expert committee. Am J Clin Nutr 64: 650-658, 1996.

54. Al-Maghrabi J, Al-Sakkaf K, Qureshi IA, Butt NS, Damnhory L, Elshal M, Al-Maghrabi B, Aldahlawi A, Ashoor S, Brown B, et al: AMPK expression patterns are significantly associated with poor prognosis in breast cancer patients. Ann Diagn Pathol 29: 62-67, 2017.

55. Khabaz MN, Al-Sakkaf K, Qureshi IA, Butt NS, Damnhory L, Elshal M, Al-Maghrabi B, Aldahlawi A, Ashoor S, Brown B, et al: Expression of p-AMPK is associated with hormone receptor phenotypes and lymph node metastasis in breast cancer. Int $\mathrm{J}$ Clin Exp Patho 10: 7044-7051, 2017.

56. Pfaffl MW, Horgan GW and Dempfle L: Relative expression software tool (REST) for group-wise comparison and statistical analysis of relative expression results in real-time PCR. Nucleic Acids Res 30: e36, 2002.

57. Livak KJ and Schmittgen TD: Analysis of relative gene expression data using real-time quantitative PCR and the 2(-Delta Delta C(T)) method. Methods 25: 402-408, 2001

58. Mandrekar JN: Receiver operating characteristic curve in diagnostic test assessment. J Thorac Oncol 5: 1315-1316, 2010 
59. Soudyab M, Iranpour M and Ghafouri-Fard S: The role of long non-coding RNAs in breast cancer. Arch Iran Med 19: 508-517, 2016.

60. Zhu Y, Mao D, Gao W, Han G and Hu H: Analysis of lncRNA expression in patients with eosinophilic and neutrophilic asthma focusing on LNC 000127. Front Genet 10: 141, 2019.

61. Fernandes JCR, Acuña SM, Aoki JI, Floeter-Winter LM and Muxel SM: Long non-coding RNAs in the regulation of gene expression: Physiology and disease. Noncoding RNA 5: 17, 2019.

62. Wei JW, Huang K, Yang C and Kang CS: Non-coding RNAs as regulators in epigenetics (Review). Oncol Rep 37: 3-9, 2017.

63. Ghafouri-Fard $S$ and Taheri M: The expression profile and role of non-coding RNAs in obesity. Eur J Pharmacol 892: 173809, 2021.

64. Butler AE, Hayat S, Dargham SR, Malek JA, Abdullah SA, Mahmoud YA, Sathyapalan T and Atkin SL: Long non-coding RNA expression in non-obese women with polycystic ovary syndrome and weight-matched controls. Reprod Biomed Online 41: 579-583, 2020

65. Liang Y, Song X, Li Y, Chen B, Zhao W, Wang L, Zhang H, Liu Y, Han D, Zhang N, et al: LncRNA BCRT1 promotes breast cancer progression by targeting miR-1303/PTBP3 axis. Mol Cancer 19: 85, 2020.

66. Sun Z, Liu J and Liu J: The expression of lncRNA-MALAT1 in breast cancer patients and its influences on prognosis. Cell Mol Biol (Noisy-le-grand) 66: 72-78, 2020.

67. Lv D, Xu K, Jin X, Li J, Shi Y, Zhang M, Jin X, Li Y, Xu J and Li X: LncSpA: LncRNA spatial atlas of expression across normal and cancer tissues. Cancer Res 80: 2067-2071, 2020

68. Mohebi M, Ghafouri-Fard S, Modarressi MH, Dashti S, Zekri A, Kholghi-Oskooei $\mathrm{V}$ and Taheri M: Expression analysis of vimentin and the related lncRNA network in breast cancer. Exp Mol Pathol 115: 104439, 2020

69. Stelzer G, Rosen N, Plaschkes I, Zimmerman S, Twik M, Fishilevich S, Stein TI, Nudel R, Lieder I, Mazor Y, et al: The genecards suite: From gene data mining to disease genome sequence analyses. Curr Protoc Bioinformatics 54: 1.30.1-1.30.33, 2016.

70. The Rnacentral Consortium, Petrov AI, Kay SJE, Kalvari I, Howe KL, Gray KA, Bruford EA, Kersey PJ, Cochrane G, Finn RD, et al: RNAcentral: A comprehensive database of non-coding RNA sequences. Nucleic Acids Res 45: D128-D134, 2017.

71. Paraskevopoulou MD, Vlachos IS, Karagkouni D, Georgakilas G, Kanellos I, Vergoulis T, Zagganas K, Tsanakas P, Floros E, Dalamagas T and Hatzigeorgiou AG: DIANA-LncBase v2: Indexing microRNA targets on non-coding transcripts. Nucleic Acids Res 44: D231-D238, 2016.

72. Wang Y, Chen L, Wu Z, Wang M, Jin F, Wang N, Hu X, Liu Z, Zhang CY,Zen K, et al: miR-124-3p functions as a tumor suppressor in breast cancer by targeting CBL. BMC Cancer 16: 826, 2016.
73. Zhu X, Rao X, Yao W and Zou X: Downregulation of MiR-196b-5p impedes cell proliferation and metastasis in breast cancer through regulating COL1A1. Am J Transl Res 10: 3122-3132, 2018

74. Wang B,Li D, Kovalchuk I, Apel IJ, Chinnaiyan AM, Wóycicki RK, Cantor CR and Kovalchuk O: miR-34a directly targets tRNAi ${ }^{\mathrm{Met}}$ precursors and affects cellular proliferation, cell cycle, and apoptosis. Proc Natl Acad Sci USA 115: 7392-7397, 2018.

75. Zhang L, Wang L, Dong D, Wang Z, Ji W, Yu M, Zhang F, Niu R and Zhou Y: MiR-34b/c-5p and the neurokinin-1 receptor regulate breast cancer cell proliferation and apoptosis. Cell Prolif 52: e12527, 2019

76. Jiang J, Yang X, He X, Ma W, Wang J, Zhou Q, Li M and Yu S: MicroRNA-449b-5p suppresses the growth and invasion of breast cancer cells via inhibiting CREPT-mediated Wnt $/ \beta$-catenin signaling. Chem Biol Interact 302: 74-82, 2019.

77. Hou L, Chen M, Yang H, Xing T, Li J, Li G, Zhang L, Deng S, $\mathrm{Hu}$ J, Zhao X and Jiang J: MiR-940 inhibited cell growth and migration in triple-negative breast cancer. Med Sci Monit 22: 3666-3672, 2016.

78. Hu Y, Zhu Q and Tang L: MiR-99a antitumor activity in human breast cancer cells through targeting of mTOR expression. PLoS One 9: e92099, 2014.

79. Wang X, Li Y, Qi W, Zhang N, Sun M, Huo Q, Cai C, Lv S and Yang Q: MicroRNA-99a inhibits tumor aggressive phenotypes through regulating HOXA1 in breast cancer cells. Oncotarget 6: 32737-32747, 2015.

80. Wang YW, Zhang W and Ma R: Bioinformatic identification of chemoresistance-associated microRNAs in breast cancer based on microarray data. Oncol Rep 39: 1003-1010, 2018.

81. Shi W, Bruce J, Lee M, Yue S, Rowe M, Pintilie M, Kogo R, Bissey PA, Fyles A, Yip KW and Liu FF: MiR-449a promotes breast cancer progression by targeting CRIP2. Oncotarget 7: 18906-18918, 2016

82. Dahariya S, Paddibhatla I, Kumar S, Raghuwanshi S, Pallepati A and Gutti RK: Long non-coding RNA: Classification, biogenesis and functions in blood cells. Mol Immunol 112: 82-92, 2019.

83. Xu S, Chen P and Sun L: Regulatory networks of non-coding RNAs in brown/beige adipogenesis. Biosci Rep 35: e00262, 2015.

84. Jiang MC, Ni JJ, Cui WY, Wang BY and Zhuo W: Emerging roles of lncRNA in cancer and therapeutic opportunities. Am J Cancer Res 9: 1354-1366, 2019.

85. Lo PK, Wolfson B, Zhou X, Duru N, Gernapudi R and Zhou Q: Noncoding RNAs in breast cancer. Brief Funct Genomics 15 200-221, 2016



This work is licensed under a Creative Commons Attribution-NonCommercial-NoDerivatives 4.0 International (CC BY-NC-ND 4.0) License. 